pesticides, for example, was won through the Environmental Defense Fund.

A third theme also is concerned with voluntary effort, and it is peculiarly British. The control of pesticides comes under a so-called Pesticides Safety Precautions Scheme which has persuaded the manufacturers voluntarily to abandon some pesticides altogether. From time to time governments are pressed to impose mandatory control (and there is still a need for it in some non-agricultural uses of pesticides), but every time the matter is looked into, the advice given (even by the Royal Commission on Environmental Pollution in its Fourth Report in 1974) is that there is no case for replacing the voluntary system.

Finally, Sheail's book has some vivid illustrations of the familiar pattern of events in environmental politics, a pattern which anyone who wants to take part in such activities has to understand. There is a prologue of silent scientific work to which politicians, even if they know about it, are indifferent. There follows a sensa- tional episode, such as the Torrey Canyon disaster, or an emotive popularization of some hazard, such as was so successfully done in Silent Spring. (It was the chairman of a Congressional subcommittee on agriculture who described the public opinion left by Silent Spring as "the worst residue problem we have to face today".) The cautious scientists, striving to solve the problems, are often bitterly criticized during this emotive phase. Then come pressures for legislation or, in the United States, lawsuits; and finally there has to be a compromise between those who want to exploit the environment for profit (either by growing crops or making pesticides) and those who want to protect it.

Above all, John Sheail's book is a record of missionary work by scientists among civil servants and politicians. There is no climax, but nor should there be: the story is not over yet.

Lord Ashby is a Fellow of Clare College, Cambridge CB2 ITL, UK. He was Chairman of the Royal Commission on Environmental Pollution from 1970 to 1973 .
Poln

\section{Viewed from above}

\section{Melbourne G. Briscoe}

Introduction to Satellite Oceanography. By G.A. Maul. Martinus Nijhoff: 1985. Pp.606. Dfl.220, \$80.

Satellite Oceanography: An Introduction for Oceanographers and Remote-sensing Scientists. By I.S. Robinson. Ellis Horwood: 1985. Pp.455. £42.50, \$63.75. Methods of Satellite Oceanography. By Robert H. Stewart. University of California Press: 1985 . Pp.368. \$38.50, £32.75.

IT WAS not so long ago that the proper background for a physical oceanographer was deemed to lie more in one's heritage and sea legs than in any particular formal education. Experience and practical apprenticeship were far more important than classes and books. In recent years it has been seen to be necessary to complement that approach of thoughtful explanation and observation with a good dose of common sense about electronic and mechanical instruments, and a solid grounding in mathematics and physics. Such mandatory education now includes the need for more than a passing knowledge of numerical methods, thermodynamics, synoptic and boundary-layer meteorology, and, depending on the chosen specialization, chemistry, geology and biology.

In this rapid evolution and expansion of formal training, however, it has been easy to forget that oceanography - even today's physical oceanography of potential vorticity balances and dispersion relations - is still mainly an observational science. Our ideas about how the ocean works are driven by what we see of its workings.
These three books bring this issue back into the limelight. They all attempt to display and explain the enormous potential of remote sensing of the oceans, principally from satellites, and to provide the information one might need to use and to understand this newly available tool. Maul aims his book at "a wide range of oceanographers, managers, and engineers" (is this a hierarchy, I wonder, and, if so, which way does it go?); Stewart says his is for "scientists with varied backgrounds"; and Robinson addresses his more eclectic book to an equally broad audience: "practising oceanographers ... sensor technologists and remotesensing specialists... and students of both oceanography and remote sensing".

The content and success of each of the books reflect the authors' backgrounds. Maul and Robinson both specialize in the infrared and optical properties (such as colour) of the sea surface, while Stewart concentrates on radio and radar scattering from the surface. Robinson's book provides some useful material on orbits and data handling, much of which is probably ephemeral, whereas Stewart has tried to include fundamental and perhaps more durable material about the basic physics of the sensors and the associated electromagnetic emission and scattering processes. Stewart's book is the most pleasing typographically, and includes a number of impressive colour plates which illustrate certain applications. Maul contains considerable detail and comes the closest to being self-contained on a number of topics. Robinson gives a lot of help to the person actually working with the data (not one of his intended audience. by the way), but a large number of typographical errors lessens one's confidence in some of his material.
In books such as these, it is unlikely that the reader will start at the beginning and read to the end; a comprehensive and detailed index is therefore essential. As a test, I tried to look up the established accuracy of sea surface temperatures as measured from a satellite, which is one of the oldest and most useful products of remote sensing. Only Robinson allows direct access to the topic via the index (but under the heading "SST"). Stewart does not even have an entry under "Temperature", although his discussion of the topic is arguably the best of the three. (Apparently, if one works very hard, it is possible to get about $1 \mathrm{~K}$ accuracy.)

The authors are all successful in their goal of making remote sensing more accessible to the oceanographer, perhaps more so as textbooks - they are all based on course notes - than as reference books. Robinson, however, mostly fails in his attempt to provide an oceanographic background for the remote senser; an entire book would be necessary for this task, and would be very difficult to write, but such a volume is clearly needed to stem the trend of space engineers publishing second-rate oceanography in nonoceanographic journals and in nonrefereed conference proceedings.

But I wonder if these books are really necessary. Even if they meet their stated goals, was the goal worth addressing? Traditionally, a new tool becomes known to the science community by its being used and by publication of the results in science journals. These authors argue. however, that here the tool (sensors on satellites) is so different, so complicated and so inaccessible in terms of its construction and its data handling, that the issue must be forced, rather than just being allowed to happen. I suppose they are right, but you cannot force good science and it is good science based on remote sensing that will ultimately sell the new tool.

There is considerable promise in satellite oceanography as a broad but not detailed observational tool; this is precisely the missing dimension in traditional oceanographic measurements, so with perseverance by all and tolerance by the traditionalists this new view may yet pay off. These books are a step in the right direction.

Melbourne G. Briscoe is an Associate Scientist in the Physical Oceanography Department, Woods Hole Oceanographic Institution. Woods Hole, Massachusetts 02543. USA.

\section{New in paperback}

- The Nature of Selection: Evolutionary Theory in Philosophical Focus by Elliott Sober. Publisher is MIT Press. price \$9.95, £9.95. For review see Nature 314, 680 (1985).

- Climate and Historv: Studies in Past Climates and Their Impact on Man edited by T. M. L. Wigley. M. J. Ingram and G. Farmer. Publisher is Cambridge University Press, price $£ 15$. $\$ 24.95$. For review see Nature 298, 499 (1982). 